\title{
Effectiveness of the ADDIE Model within an E-Learning Environment in Developing Creative Writing in EFL Students
}

\author{
Abdullah M. Almelhi ${ }^{1}$ \\ ${ }^{1}$ English department, Faculty of Languages \& Translation, King Khalid University, Saudi Arabia \\ Correspondence: Abdullah M. Almelhi, English department, Faculty of Languages \& Translation, King Khalid \\ University, Saudi Arabia.
}

Received: December 27, 2020

Accepted: January 5, 2021

Online Published: January 18, 2021

doi: $10.5539 /$ elt.v14n2p20

URL: https://doi.org/10.5539/elt.v14n2p20

\begin{abstract}
The present research aimed to examine the effectiveness of the ADDIE model as used in teaching online in the LMS of Blackboard ${ }^{\circledR}$ and its facilities such as discussion boards, forums and blogs for improving the creative writing skills of EFL college students. The researcher utilized a quasi-experimental method, involving a pretest, posttest and control group design. Sixty students were randomly selected from freshmen studying in the English department participated in the study and were assigned equally to the research groups. The experimental group was exposed to the e-learning environment, which sought to develop the students' creative writing skills while the control group was exposed to the traditional teaching method. Using a creative writing checklist and a writing test designed to assess the specific features of creative writing (originality, accuracy, self-expression, fluency, flexibility and overall writing performance for assessing creative writing in the research participants, results of t-tests and eta square statistical tests demonstrated that there were statistically significant differences between the mean scores gained by the experimental group and those obtained by the control group writing performance post-testing to the good of the experimental group participants. Conclusions and pedagogical implications were forwarded at the end of the article.
\end{abstract}

Keywords: instructional design, ADDIE model, creative writing, EFL students

\section{Introduction}

Writing is such an instrumental medium of communication that language learners use it as a way of expressing opinions, ideas, and thoughts in a creative way. As the world is changing every day and new technologies have been changing the way of writing, humans have to search for new ways that motivate language learners to cope with the requirements of the new age of technology-enabled learning; newfangled methods that would make writing instruction constructive and interactive, efficient and motivating (Bugis, 2018; Chevalier, 2011; Davis, 2013; Hung, Hwang, \& Huang, 2012; Lipschutz, 2010; Murray, 2008). Therefore, LMSs, learning management systems, a.k.a. e-learning environments, have been repeatedly claimed to have potential values in English language education possibly for several reasons. The e-learning platform can create learning opportunities for actual communication akin to real-life educational environments. The target readers of such writing output are not restricted to writing teachers but may extend to student writers' peers or other extramural colleagues in global online platforms, such as blogs, Twitter, Facebook, and other social media. These media can create emerging authors with real-life readerships.

In such an LMS and its related social media with a growing digital learners' community, students could have more opportunities to put down their ideas and thoughts while they may have interactive readers who have similar opportunities read and record their feedback unswervingly to the authors' posts (Benson \& Reyman, 2009; Du \& Wagner, 2007; Kavaliauskiené, Anusiené, \& Mažeikiené, 2006; Oravec, 2002; Ward, 2004). Research has it that using LMS platforms such as Blackboard ${ }^{\circledR}$ were reported to have improved students' writing skills and subskills, as well as project a stimulating and inspiring learning environment for developing writing competencies in language learners (Pinkman, 2005; Zheng, 2012). LMSs can also augment learners' autonomy (Ward, 2004) and offers a reliable substitute for learning logs where language students can record down their developmental endeavors at writing (Du \& Wagner, 2007).

In addition, the ADDIE model - short for analysis, design, development, implementation, and evaluation - was first put forward by the Center for Educational Technology, Florida State University in the mid-1970s. The 
ADDIE model is now technologically accepted on a large scale worldwide, and it has been researched in a plethora of studies in the West (Allen, 2017; Branch, 2018; Bugis, 2018; Lin, 2015; Peterson, 2003). Some researchers believe this model is flexible enough to be adapted to different instructional environments and, therefore, is strongly applicable for integrating technology into instruction (Davis, 2013; Hsu, Lee-Hsieh, Turton, \& Cheng, 2014; Peterson, 2003).

Research indicates that Arab EFL learners have inadequate writing skills and most of their writings are fraught with mistakes in vocabulary, grammar, mechanics and content (unity, cohesion, logical order and so on), let alone the dynamics of idea sharing. In addition, their compositions are not well-organized and lack sufficient logical development of ideas. The failure observed about incompetent writing experiences of foreign language students is due to the failure of teaching writing skills within the peripheries of writing being a means of communication for real audiences. Besides, most of the time dedicated to writing classes addressed writing skills as oral skills, with little emphasis on teaching writing as a (recursive) process. Classroom observations are supported by the review of previous studies dealing with university students' weaknesses in EFL writing skills shows that EFL students encounter many problems in writing (Abou Baker, 1996; Al-Meni, 2008; Aly, 2002; Helal, 2003; Khater, 2002; Mourtaga, 2010; Salehi et al., 2015).

In spite of the importance of writing as an essential communicative skill, there is still a weakness in the EFL creative writing skills among EFL college students. Accordingly, this study aimed to investigate the effectiveness of designing an e-learning environment after the ADDIE model on developing the creative writing skills of EFL college students.

\section{Research question:}

The main research question which informs this study reads as follows:

What is the effectiveness of using the ADDIE Model within the e-learning environment of Blackboard ${ }^{\circledR}$ in developing creative writing skills in EFL college students?

\section{Research Hypotheses:}

The following hypotheses were formulated to be tested in this study:

1. There is a statistically significant difference between the posttest mean scores of the experimental group and the control group in writing skills that feature originality in favor of the experimental group at the 0.01 level.

2. There is a statistically significant difference between the posttest mean scores of the experimental group and the control group in writing skills that feature accuracy in favor of the experimental group at the 0.01 level.

3. There is a statistically significant difference between the posttest mean scores of the experimental group and the control group in writing skills that indicate self -expression in favor of the experimental group at the 0.01 level.

4. There is a statistically significant difference between the posttest mean scores of the experimental group and the control group in writing skills that feature fluency in favor of the experimental group at the 0.01 level.

5. There is a statistically significant difference between the posttest mean scores of the experimental group and the control group in writing skills that feature flexibility in favor of the experimental group at the 0.01 level.

6. There is a statistically significant difference between the posttest mean scores of the experimental group and the control group on the overall creative writing test scores in favor of the experimental group at 0.01 level.

\section{Research Objectives:}

The present research sought to:

1. Identify the creative writing skills necessary for EFL college students.

2. Develop an e-learning strategy-based on Writing I (Writing it Academically), manipulating the e-learning environment of Blackboard to develop creative writing skills in first-year EFL college students.

3. Measure the effectiveness of the proposed instructional strategy in the Blackboard environment to 
develop the creative writing skills in first year EFL college students.

\section{Research Methodology}

This research was planned after a pretest-posttest control group design in a quasi-experimental setting. For this research design, the researcher used a randomly selected sample of 60 students (30 students for the experimental group and 30 students for the control group), all having been freshmen in the English Program. Both groups passed through the designed pre-testing and posttesting procedures. The experimental group participants were taught Writing I - an introductory upper-intermediate course in academic writing through the LMS of Blackboard according to the steps of ADDIE model of instructional design, which sought to develop the students' creative writing skills. The control group was taught Writing I in the conventional f2f teaching method.

\section{Instruments of the Research}

The following instruments were used in the following research Writing.

\section{a) A Creative Writing Skills Checklist (CWSC):}

This CWSC was developed and validated by the researcher; the construct validity was determined by a panel of (9) expert EFL instructors in the English department well-versed in online teaching and writing instruction to examine the scale items and decide on which items were specifically apposite for measuring which creative writing skills were appropriate for this level of proficiency. The CWSC was designed to assess students' creative writing skills before and after instruction into the Writing I course delivered in the Blackboard LMS and the ADDIE model. The CWSC scores in the validation study were compared against pilot study students' first semester scores ( $\mathrm{N}=77$ male students) in Writing and their GPAs to measure the discriminant validity of the checklist. Interrater reliability calculated through intra-sample correlation coefficient for all cases was 0.66 . Internal reliability was determined by computing the Cronbach alpha found out to be $>0.70$ for all binary checklist items across all cases. The discriminant validity of the CWSC was calculated based on the Pearson correlation coefficient which revealed that the overall score from the checklist correlated well with the component features of creative writing scores $(r=.68$.).

\section{b) A Pre-post Creative Writing Skills Test (developed and validated by the researcher).}

Nine raters were involved in measuring 77 students' sample writings in the pilot study. The Creative Writing Skills Test (CWST) is made up of five domains, namely: originality, flexibility, elaboration, and organization. Test-retest reliabilities computed for the CWST overall cases' scores averaged 0.67 ; the average inter-rater reliability coefficient was 0.85 , thus indicating that the test remained consistent over time, and is reliably scorable by different raters. Furthermore, a Cronbach's alpha coefficient was generated for the pilot study sample writings' scores, yielding an $\alpha$ of $0.89(\mathrm{~N}=77)$, which suggests that the general internal consistency reliability of this test was good, given the item number and inter-item correlations.

\section{Research Procedures:}

The following procedures were followed:

1. Identifying, listing and validating a checklist of EFL creative writing skills required for first year EFL college students.

2. Identifying the procedures and the evaluation techniques during implementation.

3. Developing an e-learning strategy grounded in Academic Writing Book I and derives its objectives from the elements of an e-learning strategy that functionally manipulates the technology of Blackboard online environment, the Book I content, course administration and support, communication and evaluation.

4. Modifying and setting the strategy in its final form according to suggestions of other instructors and reviewers.

5. Developing and validating a writing test and a rubric for correcting it for assessing first year EFL college students' writing skills.

6. Teaching the experimental group according to the e-learning strategy and the control group by using the traditional method.

7. Administering the creative writing test to both groups for post testing.

8. Reporting and discussing results and presenting recommendations. 


\section{Instructional Procedures}

Experimental students were requested to build their own blogs after they had been guided on how to establish their personal blogs. The instructional model for using blogs for learning creative writing has been that of ADDIE (Analysis, Design, development, implementation and evaluation), which was incorporated in the weblog design process.

1. Analysis: Students gather information from open-source internet materials and readings through search engines. They use these sources to collect data and ideas for their essays and for designing their weblogs according to each writing project's objectives, content, activities and tasks.

2. Design: Students were asked to attend to the steps of the creative writing process, its techniques, activities and tasks, as well as the drafting, editing and revising for mechanics and content phases of the creative writing process.

3. Development: Students were directed as to how to build their own web blogs of creative writing out of online accessible resources.

4. Implementation: The researcher implemented pre writing achievement test as a diagnostic test in order to find out the weakness points students faced. At this stage, students were trained as to how to develop their essays and publish them in their blogs cooperatively, yet correctly.

5. Evaluation: Students under the assistance and supervision of the researcher were guided to conduct systematic and organized assessment of their peers' and their own works to achieve the objectives of each writing project.

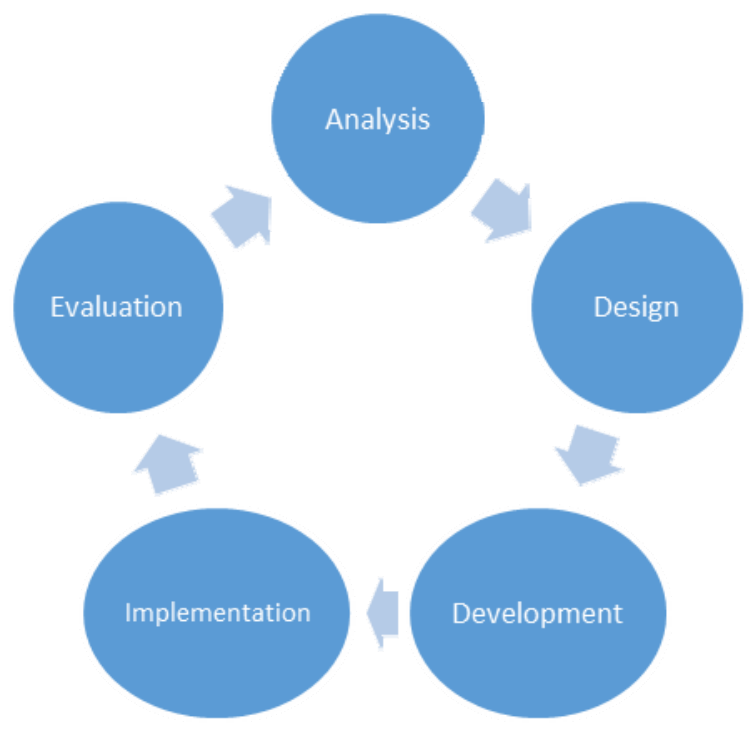

Figure 1. The ADDIE Model. Adapted from Allen, 2017, p. 75

Then they were introduced with the writing tasks and activities in the writing topics assigned to them. In each class session, they were given a writing topic as a discussion thread on Blackboard. They were assigned the specific writing tasks such as brainstorming ideas, listing, freewriting, developing advance organizers, etc. The activities and tasks were graded across the different phases of the writing process including the pre-writing phase (such as deciding on a writing topic/title, listing, creating graphic organizers, and other relevant brainstorming tasks), the writing per se phase (developing the essay outline, writing the first draft, and writing a second and/or third draft), and the post-writing phase (peer-proof, peer-draft reading, revising and editing in collaborative work) and final writing (writing the final draft). These tasks and activities were recycled by the students in the different phases by publishing their products online. These steps are summarized in the diagram below. 


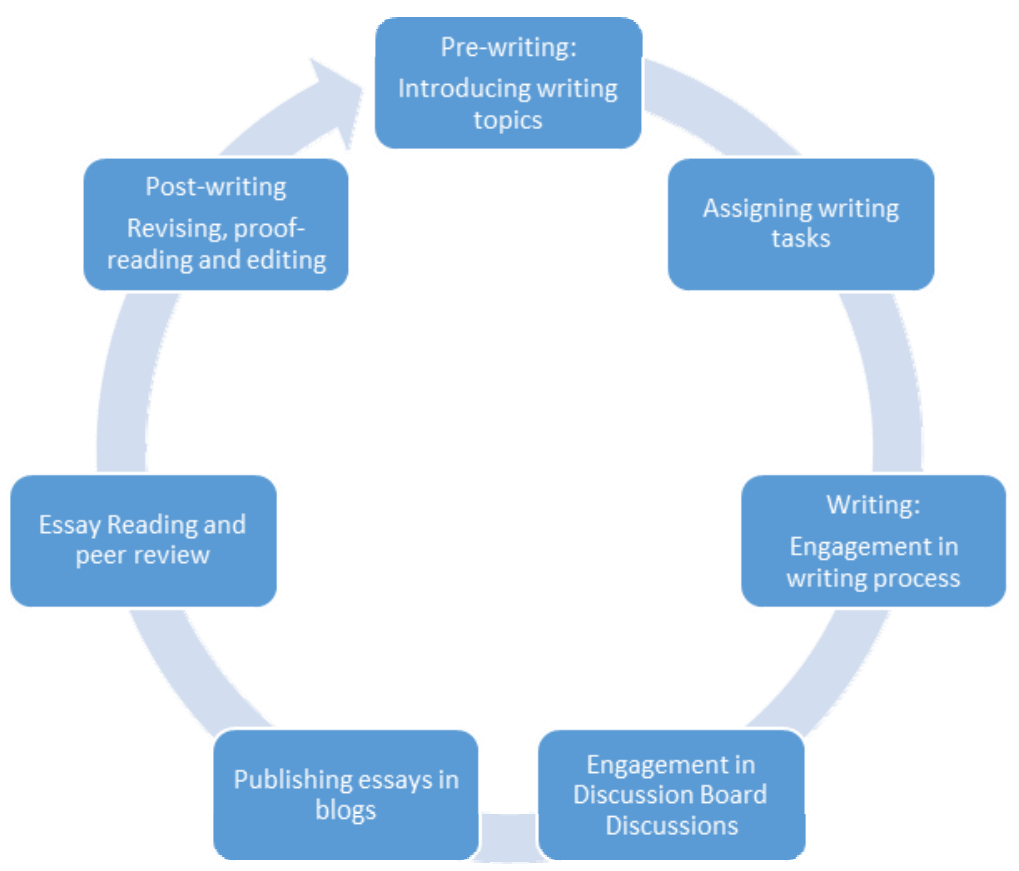

Figure 2. The Instructional Creative Writing Process

\section{Literature Review}

\subsection{Instructional Design Models}

From a pedagogical perspective, e-learning environments were suggested as effective platforms equipped with all necessary tools for teaching writing to foreign language learners; such platforms can help encourage learners to reflect on their writing experiences and also to add comments to extramural posts to encourage further reflection in an active, interactive writing community (Mynard, 2007). Moreover, these platforms can brush up on the students' analytical and critical thinking skills (Oravec, 2003; Zhang, 2009).

Language educators, therefore, suggested several models of instructional design to inform potentially effective teaching and learning. Such instructional paradigms include the ADDIE model (short for analysis, design, develop, implement, and evaluate), the ACE model (acronym for analyze, create, and evaluate), the IDEA model (initializing interview, design, embed, and assess) and the Dick \& Carey model, also called the three-phase design model (Allen, 2017; Bugis, 2018; Dick, Carey, \& Carey, 2001; Davis, 2013).

Such designs as the ones earlier mentioned are linear and prescriptive indicating a series of steps that inform the instructional design process from the inception to the end. Other models are recursive and reflective which build on the identification, analysis and subsequent anatomy of 'learning tasks into simpler subtasks' that guide the design of instruction and teaching materials (Allen, 2017, p. 71).

Campbell (2014) explained that the ADDIE model is an instructional design whose idea inspired many curriculum designers to suggest other forms and design models because the ADDIE paradigm models a systematic structure of instruction in terms of its liability to accessible, plannable design, modification and evaluation. It also links theory and practice with the incorporation of instructional technology, lending itself to extensive research (Campbell, 2014; Chevalier, 2011; Davis, 2013; Khadimally, 2015; Wang \& Hsu, 2009). In LMSs, the tools of such systems like Blackboard can be redesigned or rearranged in flexible phases of instruction (Moradmand, Datta, \& Oakley, 2014; Wiphasith, Narumol, \& Sumalee, 2016).

\subsection{E-learning: Concepts and Characteristics}

According to Henry (2001), e-learning refers to the instructional design of the Internet or internet applications to provision or support the delivery of course knowledge, skills or competencies in a holistic approach not limited to any particular subject matter, technologies, or infrastructures. In a similar tone, Codone (2001) described e-learning as any type of online or off-line learning delivered electronic formats as on a computer, an intranet, the open internet, satellite, or any other similar technologies. By the same token, Naidu (2006) explained that e-learning normally refers to the planned use of networked information and communications technology (ICT) or 
Information Technology (IT) for teaching and learning purposes. E-learning is also referred to as online, web-based, networked, virtual, or distributed learning (Maddison \& Kumaran, 2017).

Theorists classified the general approaches to e-learning into two categories (Ghirardini, 2011): self-paced e-learning where students, usually more 1000 enroll in self-paced learning per semester and can get support synchronously and asynchronously in an independent manner (Hall \& Getts, 2017) and facilitated/instructor-led learning (ILL), in which the curriculum is developed and delivered in a linear model by integrating the course content elements and activities chronologically (FAO, 2011). Characteristically, e-learning courses may work according to one approach or usually include both approaches. Other theorists (e.g., Itmazi \& Gea, 2005) recognized three distinctive approaches to e-learning: 1) the enhanced approach in which students' learning is facilitated, scaffolded and enhanced by face-to-face (f2f) learning in the medium of web-based technology (LMSs). This approach may reduce face-to-face seat time (f2f) in real-life academic settings, but it should not exceed $24 \%$ of course delivery time; 2 ) the blended Learning approach, akin to the enhanced approach, mixes conventional face-to-face with online learning, with, consequently, a substantial portion of content being delivered online (about more than $25 \%$ to $74 \%$ of the course time); 3 ) the full online approach which replaces face-to-face classroom meetings with totally virtual learning (VL). This approach could have some face-to-face meetings for examinations or other activities, but more than $75 \%$ of the course content must be delivered in the LMS medium. Currently due to the COVID-19 pandemic, the full online approach is strictly followed $100 \%$, including exams which are run online from home or on campus.

For e-learning to be effective, Ghirardini (2011) suggested that the value and practicability of the e-learning course could be improved adapting the course content and activities to be:

1. Commensurate with learner-paced, learner-centered learning in a relevant and specific manner that caters to the in learners' needs, roles and everyday jobs suitable for their professional life;

2. Assimilable and granular enough to be open for including new knowledge and skills by allowing flexible scheduling of learning;

3. Engaging where content, teaching and evaluation methods are creatively designed to provide motivating and engaging learning experiences;

4. Interactive to promote collaborative peer-learning, guided-teaching, and on-time teacher mentoring and monitoring;

5. Personally-adjustable so as to create a self-paced, customizable e-course that caters to the needs of individual students, individual differences while helping instructors to monitor and evaluate the learners' performance and progress.

Ghirardini (2011) further explains that e-learning should involve adaptation of the course content to include interactive materials and lesson simulations. It should also provide supportive online services such as e-tutoring, e-coaching and e-mentoring to guide learners through their pedagogical experiences. E-learning should also be constructed around collaborative learning activities including discussion boards, knowledge-sharing and cooperative teams who can make use of the LMS built-in learning tools such as discussion boards, forums, blogs, and YouTube mashups, all practiced in virtual classrooms, directed and mentored by the teacher. Such features of e-learning highlighted by Ghirardini (2011) are thought to be instrumental for all effective online learning as when considered carefully by course designers and instructors, it can help them to build instructionally sound and successfully effective e-courses.

\subsection{Creative Writing $(C W)$ : Using E-Learning Platforms for Enhancing $C W$}

Furthermore, previous studies showed that using technology can be contributory to developing creative writing as most of the students are keen on using technology generally and using internet-driven learning specifically (Fageeh, 2011; Ceserani, 2014; Elola \& Oskoz, 2010; Ibnian, 2009; Jameel, 2017; Thatcher, 2000). The review of pertinent literature indicated that using technology in creative writing can be beneficial in the following aspects:

1- Interactive websites enhance creative writing skill (e.g., Tsai, 2006).

2- Using interactive webs provide a highly effective frame for writing such as blogs, wikis and email (e.g., Fageeh, 2011; Elola \& Oskoz, 2010)

3- E-learning environments provide a kind of collaborative environment (e.g., Forsythe, 2014).

OnTaura and Nagai (2010) defines creative writing as writing whose aim is to communicate the inner thoughts, feelings and emotions of writers in novel, original and elaborate ways instead of simply relaying facts and 
information in straightforward language. This process involves student-writers being able to tolerate with ambiguity, a skill direly needed in cyberspace (Harper, 2006; Kulprasit \& Chiramanee, 2012). Schlepphege (2009) describes creative writing as putting one's ideas and feelings about a particular topic on paper by using their imagination spontaneously at will. According to Temizkan (2011), creative writing skills, in this vein, refer to the abilities of freely expressing original imagination with respect to a certain topic on a particular form of writing. Creative writing ability, therefore, involves extending beyond the ordinary, yet without departing from the established normal values of written discourse. Creative writing also involves producing novel, unprecedented, unique ideas seen at the time they are produced as different from existing ideas known in a particular field.

Creative writing skills are also seen to be related to specific abilities, namely, flexibility, elaboration, proficiency and fluency, which are essential for language students in helping them formulate their thoughts and ideas verbally or in writing in a meaningful and logical arrangement commensurate with the four specific abilities just mentioned (Alothman, 2012; Awamleh et al., 2012). In this regard, researchers (e.g., Kulprasit \& Chiramanee, 2012; Khansir, 2012) identified and elaborated on the features of creative writing, a summary of which is presented as follows:

1. Originality: The ability of the writer to come up with the new ideas that is unique and unrepeated both to him/her and the reader. The less common ideas are the more original they are. Such unusual ideas attract the reader's attention.

2. Flexibility: The ability of the writer to produce variety of ideas as possible as $\mathrm{s} / \mathrm{he}$ can. Then, $\mathrm{s} / \mathrm{he}$ can choose the best ideas to support the main idea of his/her product.

3. Elaboration: Expanding of the writer's ideas, giving specific details at high level of analysis.

4. Choice of words: Creativity manifests itself in the choice of words in the ways which students build words together to communicate ideas. Creative writing can be a valuable tool in helping students learn about the power and pleasure of words.

5. Organization: The writer organizes ideas in a logical way that helps the reader follow the order of thoughts easily without frustration resulted from disorder.

In fine, prior research in EFL contexts have pointed to the positive gains of e-learning environments such as e-learning platforms in different language learning areas such as reading and writing (e.g., Lin, 2011; Mohammed, 2009). This research showed that e-learning environments were suitable and is highly recommended for use in the foreign language classroom. Furthermore, researchers outlined variant suggestions and recommendations to enhance EL learning in general and EFL learning in particular.

\section{Results and Discussion}

The results of the present study are here presented as per each hypothesis to be followed by a short explanation for the results below.

\section{Hypothesis One}

To verify the first hypothesis suggesting that "there is a statistically significant difference between the posttest mean scores of the experimental group and the control group in writing skills that feature originality in favor of the experimental group at the 0.01 level", a $t$-test for independent samples was used to compare the mean scores of the two groups on the skill of originality in the posttest.

Table 1. $t$-Test Results of the Writing Skills Featuring Originality Post- Test Comparing the Control and Experimental Groups' Mean Scores

\begin{tabular}{lllllll}
\hline Group & $\boldsymbol{n}$ & Mean & SD & D.F. & $\boldsymbol{t}$-Value & Effect Size $\left(\eta^{2}\right)$ \\
\hline Control & 30 & 9.70 & 3.087 & 58 & $7.65 *$ & $0.703 * *$ \\
Experimental & 30 & 14.57 & 1.61 & & & \\
\hline
\end{tabular}

* Significant at the 0.01 level ** High effect size

Table (1) shows that the calculated $t$-value (7.65) is statistically significant at the 0.01 level of confidence. Therefore, it becomes evident that there is a statistically significant difference between the mean scores of the experimental and control groups on the skill of originality post-test in favor of the experimental group. So, the first hypothesis is accepted. Furthermore, effect size value was high as $\eta 2=0.703$. Thus, the suggested strategy had a high effect on the participants' performance. 
The following figure demonstrates the difference between the mean scores of the post administration for both groups.

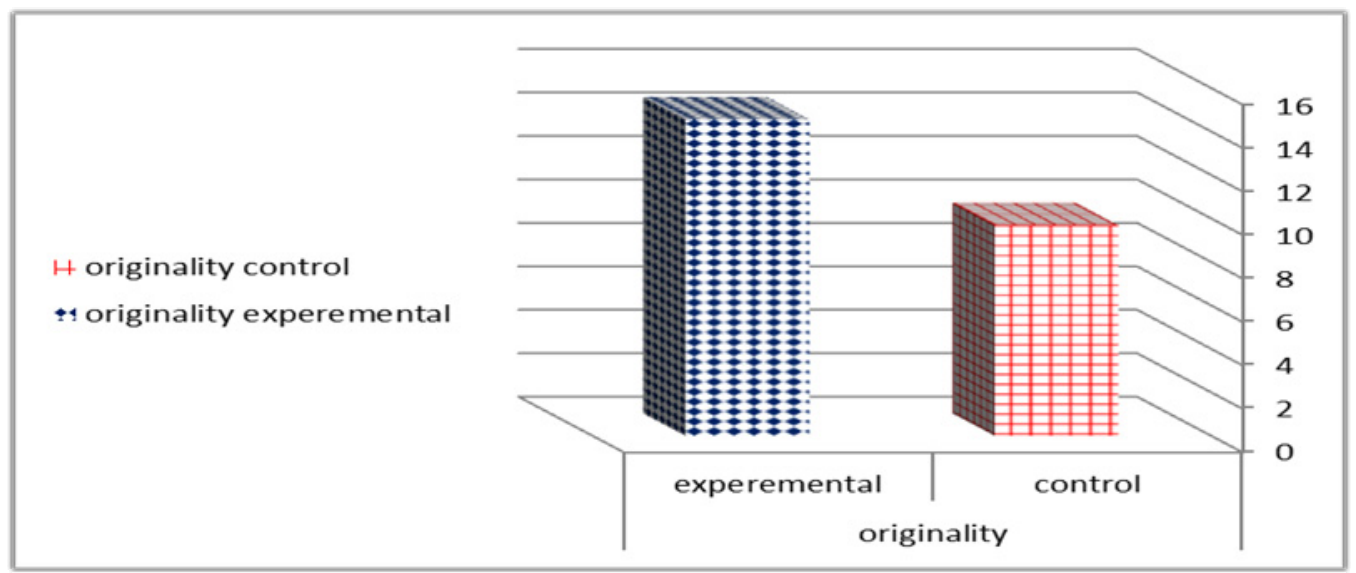

Figure 3. Comparison of Mean Scores of the Two Groups in the Post Administration of the Originality Skill

The explanation for this result could be that the e-learning approach to teaching English to the students in the experimental group has been one, amongst a few earlier ELT methods, which views language as the means of communication in an interactive learning environment (McKay, 2011; Wang, 2013). The e-learning environment could help learners in this group originally communicate efficiently using appropriate linguistic and grammatical structures in conversational language situations, where students are required to supply a variety of ideas in the communicative language tasks and practices. This finding confirms previous research findings which indicated that writing is an essentially creative process involving the three aspects of creativity - producer, product, and process, and that writing is a problem-solving activity for EFL learners to discover about novel solutions (Atkinson, 2003; Larsen-Freeman, 1997; Zamel, 1982; 1983). This could be due to the strategies used which helped learners to engage in brainstorming sessions, being open to toleration with ambiguity, collecting ideas and exploring alternatives, having sufficient time with home e-learning activities, reading widely at home online and assuming a broad perspective to thinking and writing (Harper, 2006; Kulprasit \& Chiramanee, 2012).

\section{Hypothesis Two:}

It was proposed that there was a statistically significant difference between the posttest mean scores of the experimental group and the control group in the skill of accuracy in favor of the experimental group at 0.01 level. To verify this hypothesis, $t$-test for independent samples was used to compare the mean scores of the two groups on the skill of accuracy in the posttest.

Table 2. t-Test Results of the Writing Skills Featuring Accuracy Post- Test Comparing the Control and Experimental Groups' Mean Scores

\begin{tabular}{lllllll}
\hline Group & $\boldsymbol{n}$ & Mean & SD & D.F. & $\boldsymbol{t}$-Value & Effect Size $\left(\eta^{2}\right)$ \\
\hline Control & 30 & 12.17 & 3.27 & 58 & $5.77 *$ & $0.59 * *$ \\
Experimental & 30 & 16.20 & 1.98 & & & \\
\hline
\end{tabular}

* Significant at the 0.01 level ** Medium effect size

Table (2) shows that the calculated $t$-value (5.77) is a statistically significant at the 0.01 level of significance. Therefore, it becomes evident that there is significant difference between the means of the scores obtained by experimental and control participants on the skill of accuracy on post-testing to the good of the experimental group participants. Hence, the second hypothesis is confirmed. Furthermore, the effect size value was identified as medium where $\eta^{2}=0.59$. Thus, the ADDIE model design in the LMS medium of Blackboard proved to have a medium effect on the participants' performance in creative writing.

The following figure demonstrates the difference between the mean scores of the post administration for both groups. 
S゙ accuracy control

III accuracy experemental

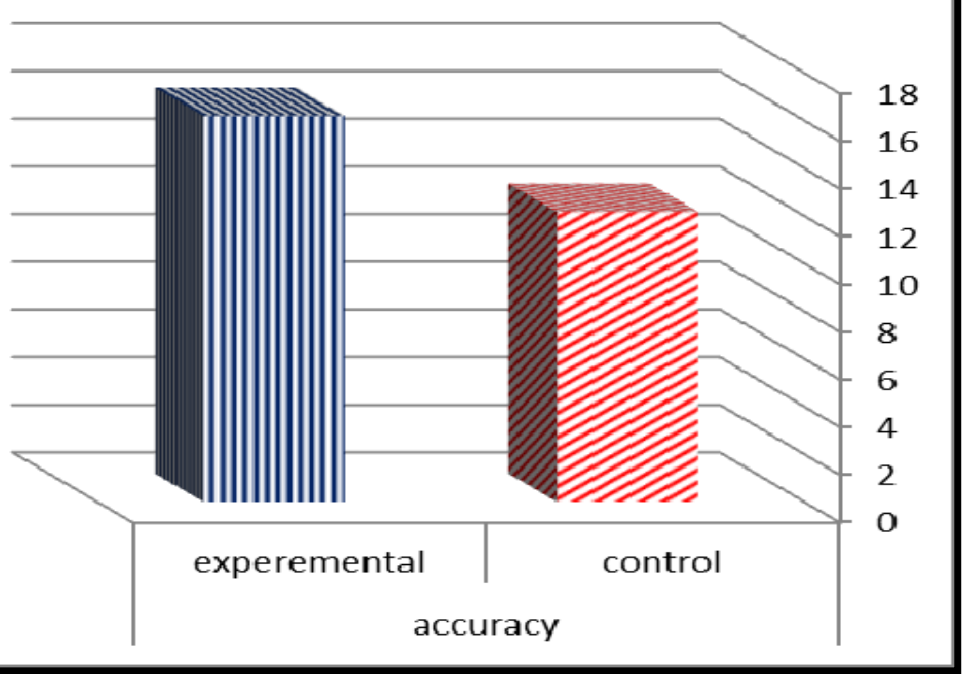

Figure 4. Comparison of Mean Scores of the Two Groups in the Post Administration of the Accuracy Skill

Common sense and experience supported by findings from the present study indicate that e-learning could encourage writing competence in approximate precision which is the result of accuracy attained in online communicative EFL classrooms which is associated with creativity - an important criterion of which is fluency of ideas. Providing EFL learning materials in e-learning environments after the instructional model of ADDIE could help in effective creative writing through nurturing accuracy and fluency (Alothman, 2012; Fageeh, 2011; Elola \& Oskoz, 2010).

\section{Hypothesis Three:}

Further, it was suggested that there was a statistically significant difference between the experimental and control participants' mean scores upon post-testing in the skill of self -expression to the good of the experimental group participants $(\alpha=0.01)$. To (dis)confirm this hypothesis, a $t$-test for independent samples was computed to compare the mean scores of the two groups' participants on their ability of self -expression upon posttesting.

Table 3. $t$-Test Results of the Self-Expression Skill Post- Test Comparing the Control and Experimental Groups' Mean Scores

\begin{tabular}{lllllll}
\hline Group & $\boldsymbol{n}$ & Mean & SD & D.F. & $\boldsymbol{t}$-Value & Effect Size $\left(\eta^{2}\right)$ \\
\hline Control & 30 & 9.13 & 3.14 & 58 & $6.73 *$ & $0.66 * *$ \\
Experimental & 30 & 13.80 & 2.12 & & & \\
\hline
\end{tabular}

\section{* Significant at the 0.01 level ** High effect size}

Table (3) indicates that the calculated $t$-value (6.73) is statistically significant at an alpha of 0.01 . Therefore, it becomes evident that there is statistically significant difference between the mean scores of the participants in the experimental and control groups on the self-expression skill upon post-testing to the good of the experimental group. Therefore, the third hypothesis is accepted. Furthermore, effect size value was high as $\eta^{2}=$ 0.66. Thus, the suggested ADDIE model of instructional design within the LMS of Blackboard had a high effect on the participants' performance.

The following figure demonstrates the difference between the mean scores of the post administration for both groups. 


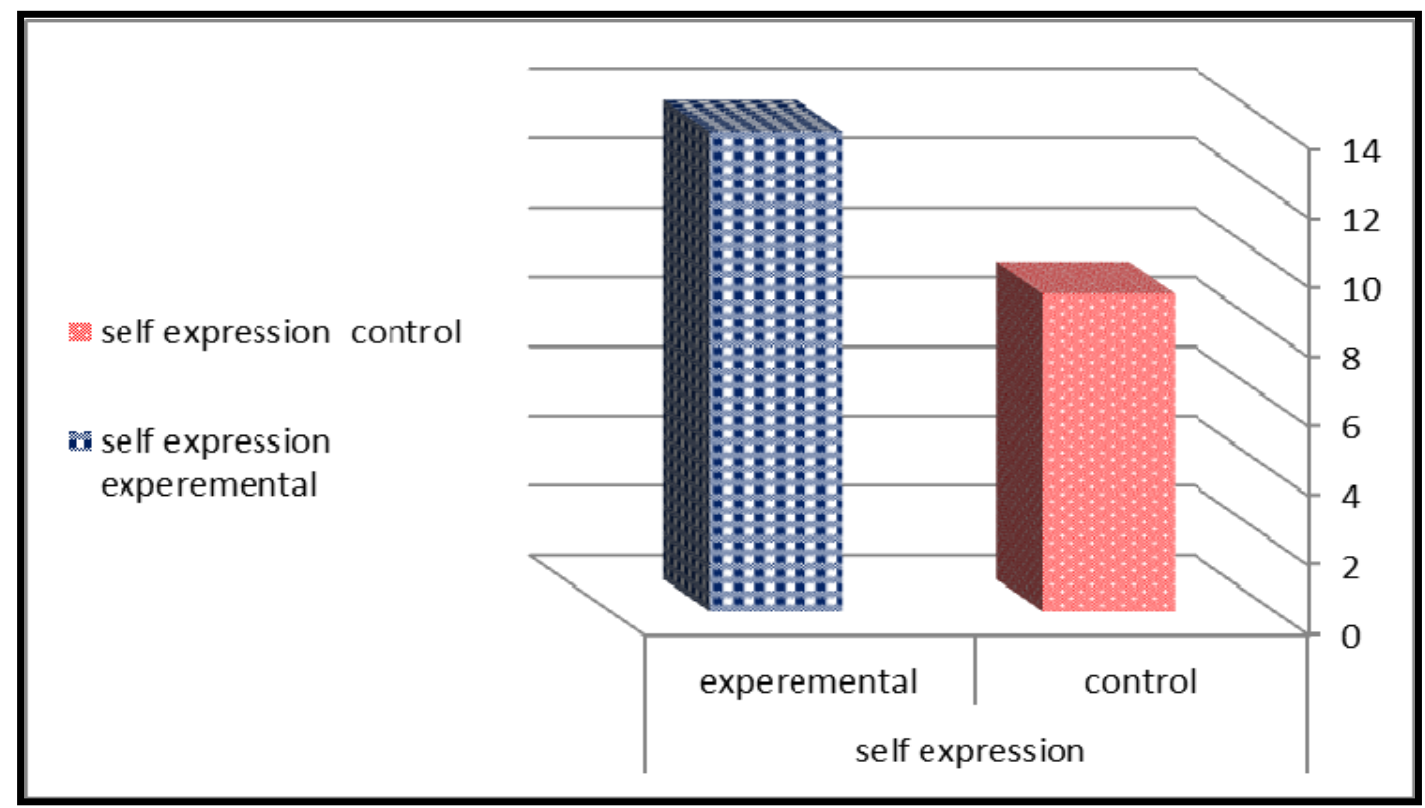

Figure 5. Comparison of Mean Scores of the Two Groups in the Post Administration of the Self-Expression Skill

E-learning environments provide a rich milieu for developing creative self-expression in writing. Students can use pre-writing stage as a plan to apply during writing stage using self-expression and reflecting on their writing in post writing stage. E-learning promotes the development of functional language used in everyday language situations (Savignon, 1991; Sato \& Kleinsasser, 1999; Densky, 2003). The e-learning environment provided both students and teachers with an authentic task, as e-learning activities in the different states of pre-writing and writing phases are now common and have become a relevant and credible forum for people to express their opinions and share information throughout the world. In this environment, experimental students could promote writing fluency by encouraging students to recycle vocabulary and to notice their language use. Recycling vocabulary became evident in student writings in the e-learning environment through the recursiveness of the ADDIE instructional model.

\section{Hypothesis Four:}

It was further hypothesized that there was a statistically significant difference between the posttest mean scores of the experimental group and the control group in the skill of fluency in favor of the experimental group at the 0.01 level. To test the verity of this hypothesis, $t$-test for independent samples was used to compare the mean scores of the two groups in the skill of fluency in the posttest.

Table 4. t-Test Results of the Skill of Fluency Post- test Comparing the Control and Experimental Groups' Mean Scores

\begin{tabular}{lllllll}
\hline Group & $\boldsymbol{n}$ & Mean & SD & D.F. & $\boldsymbol{t}$-Value & Effect Size $\left(\eta^{2}\right)$ \\
\hline Control & 30 & 11.07 & 2.81 & 58 & $5.89 *$ & $0.604 * *$ \\
Experimental & 30 & 15.23 & 2.67 & & & \\
\hline
\end{tabular}

* Significant at the 0.01 level ** High effect size

Table (4) illustrated that the calculated t-value (5.89) is statistically significant at an alpha of 0.01 . Therefore, it becomes evident that there is a statistically significant difference between the mean scores of the experimental and control groups on the fluency skill in the post-test in favor of the experimental group. Hence; the fourth hypothesis is accepted. Furthermore, the effect size value was high as $\eta^{2}=0.604$. Thus, the suggested ADDIE model for instructional design had a high effect on the participants' performance.

The following figure demonstrates the difference between the mean scores of the post administration for both groups. 


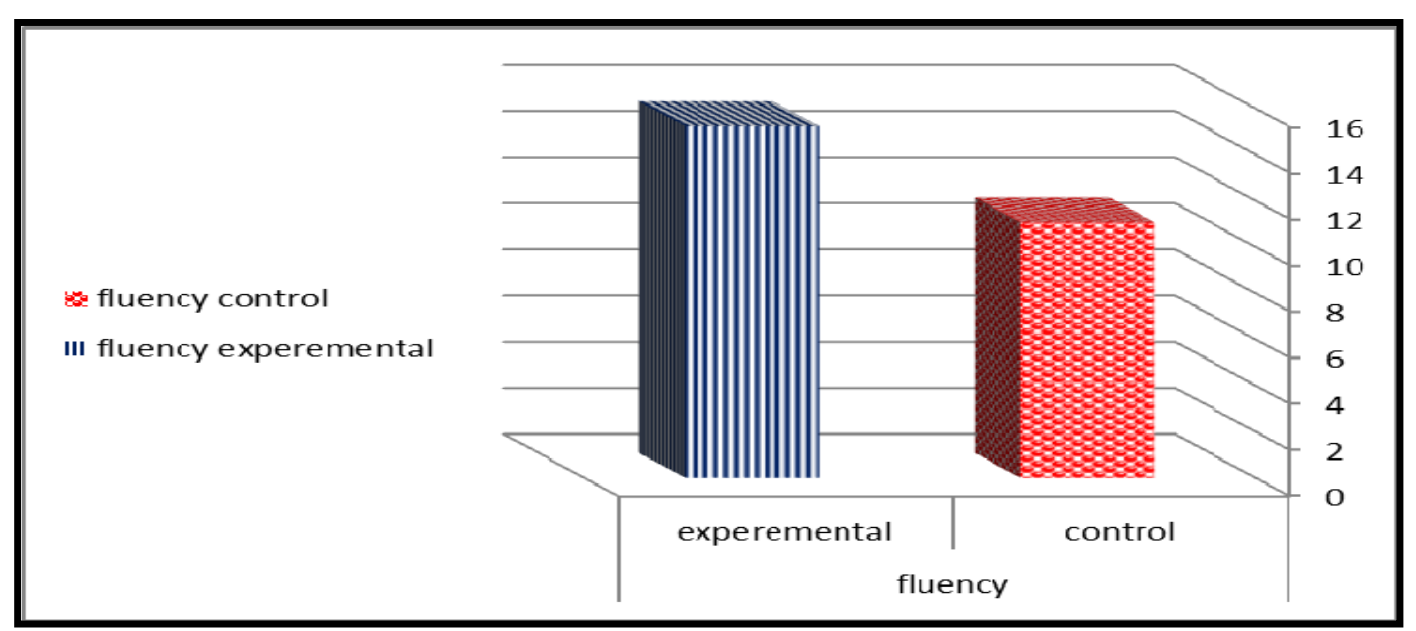

Figure 6. Comparison of Mean Scores of the Two Groups in the Post Administration of the Fluency Skill

The e-learning environment instructionally designed after the ADDIE model for teaching writing in this experiment could provide sufficient time online and offline for student writers to get sufficient training on creative writing and to get help on enhancing their fluency skill in writing. The instructional design of the ADDIE model could assist students develop their writing skills as the LMS e-learning environment with such a design helped them get motivated to write creatively. The e-community of writers in the LMS of Blackboard with the recursiveness of the steps of the ADDIE model assisted teachers and student writers to receive continued feedback for improving their particular writing abilities on an individual basis. The ADDIE model as an instructional design and the power of the LMS helped create an online learning community where students learned from their peers while the writing instructor stood as a fellow writer more than just a summative evaluator of students' written works (AlAamri, 2010; Aljumah, 2011; Ismail, et al., 2012; Jameel, 2017; Karuri, 2012).

\section{Hypothesis Five:}

Furthermore, the researcher postulated that there was a significant difference between the posttest mean scores of the experimental group and the control group in the skill of flexibility in favor of the experimental group at the 0.01 level of significance. To confirm the verity of this hypothesis, a $t$-test for independent samples was used to compare the mean scores of the two groups in the flexibility skill in the posttest. The results of the t-test proved to be statistically consistent with the hypothesis. Furthermore, effect size value was high as $\eta^{2}=0.67$. Thus, the suggested ADDIE model had a high effect on the participants' performance.

Table 5. $t$-test Results of the Skill of Flexibility Post- test Comparing the Control and Experimental Groups' Mean Scores

\begin{tabular}{lllllll}
\hline Group & $\boldsymbol{n}$ & Mean & SD & D.F. & $\boldsymbol{t}$-Value & Effect Size $\left(\eta^{2}\right)$ \\
\hline Control & 30 & 13.20 & 2.85 & 58 & $6.92 *$ & $0.67 * *$ \\
Experimental & 30 & 17.40 & 1.69 & & & \\
\hline
\end{tabular}

* Significant at the 0.01 level ** High effect size

Table (5) indicated that the calculated $t$-value (6.92) is statistically significant at the 0.01 level of significance. Therefore, it becomes evident that there is statistically significant difference between the mean scores of the experimental and control groups on the flexibility skill in the post-test in favor of the experimental group. Hence, the fifth hypothesis is accepted. Furthermore, the effect size value was high where $\eta^{2}=0.67$. Thus, the suggested strategy had a high effect on the participants' performance. The following figure demonstrates the difference between the mean scores of the post administration for both groups. 


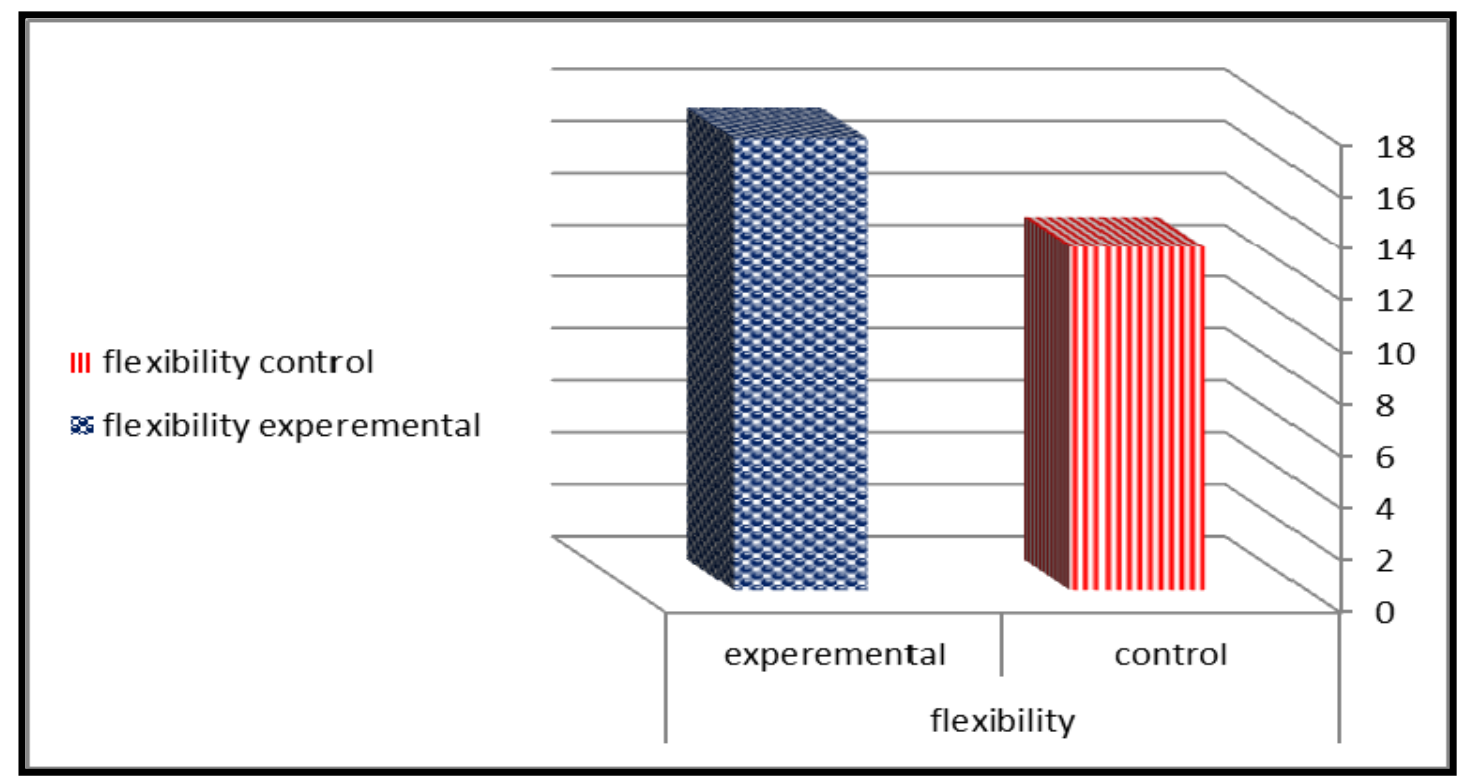

Figure 7. Comparison of Mean Scores of the Two Groups in the Post Administration of the Flexibility Skill

Flexibility is a higher-order thinking skill deemed to be crucial for learning in technology-enhanced environments. Prior research considered 'flexibility' as one of the four basic functions of divergent thinking, together with elaboration, fluency, and originality (Guilford, 1967, Torrance, 1974). The environments of LMSs were frequently cited in prior research findings as having significant effects on the development of students' abilities to create imaginative expression and produce signs of divergent thinking when students endeavored to write in search for identity or in instances when they were trained to write and read on personal topics (Topkins, 1982). Flexible thinking refers to the particular characteristic of thinking as open-mindedness in a way that helps learners adapt and conform to new learning methods and mediums. By enhancing the ability to naturally rearrange bits of knowledge, in novel and unique ways, to adaptively respond to the demands of changing situations, the study could prove that the ADDIE model in the e-learning medium of Blackboard improved cognitive flexibility during the writing process. In fact, flexibility is an instrumental ability required for adjusting to the demands of the new e-learning environments, for relocating and recycling knowledge in new situations, and for decoding and resolving unfamiliar problems. This could be explained by three main elements which specify the learners' natural tendencies to think in flexible ways in technology-driven e-learning milieus. These elements were identified as: 1) Acceptance of new or changing technologies (Technology acceptance); 2) Open-mindedness to others' ideas (Open-mindedness), and 3) Adapting to changes in learning situations (Adapting to new situations).

\section{Hypothesis Six:}

Postulating that there is a statistically significant difference between the posttest mean scores of the experimental group and the control group in overall creative writing test scores to the good of the experimental group at the 0.01 significance level, the researcher further sought to test the validity of this hypothesis with a $t$-test for independent samples. This test was used to compare the mean scores of the two groups in the creative writing skills on posttesting. The results of the $t$-test were conformed to be statistically consistent with the hypothesis.

Table 6. $t$-Test Results of All Creative Writing Skill Post- Test Comparing the Control and Experimental Groups' Mean Scores

\begin{tabular}{lllllll}
\hline Group & $\boldsymbol{n}$ & Mean & SD & D.F. & $\boldsymbol{t}$-Value & Effect Size $\left(\eta^{2}\right)$ \\
\hline Control & 30 & 55.27 & 10.59 & 58 & $9.14^{*}$ & $0.76 * *$ \\
Experimental & 30 & 77.20 & 7.78 & & & \\
\hline
\end{tabular}

* Significant at the 0.01 level ** High effect size

Table (6) displayed that the calculated $t$-value (9.14) is statistically significant at the 0.01 level of confidence. Therefore, it becomes evident that there is a statistically significant difference between the mean scores of the experimental and control groups on all creative writing skills in the post-test in favor of the experimental group. 
Therefore, the sixth hypothesis is confirmed. Furthermore, the effect size value was high where $\eta 2=0.76$. Thus, the suggested strategy had a high effect on the participants' performance. The following figure demonstrates the difference between the mean scores of the post administration for both groups.

\section{宦 total control \\ win total experemental}

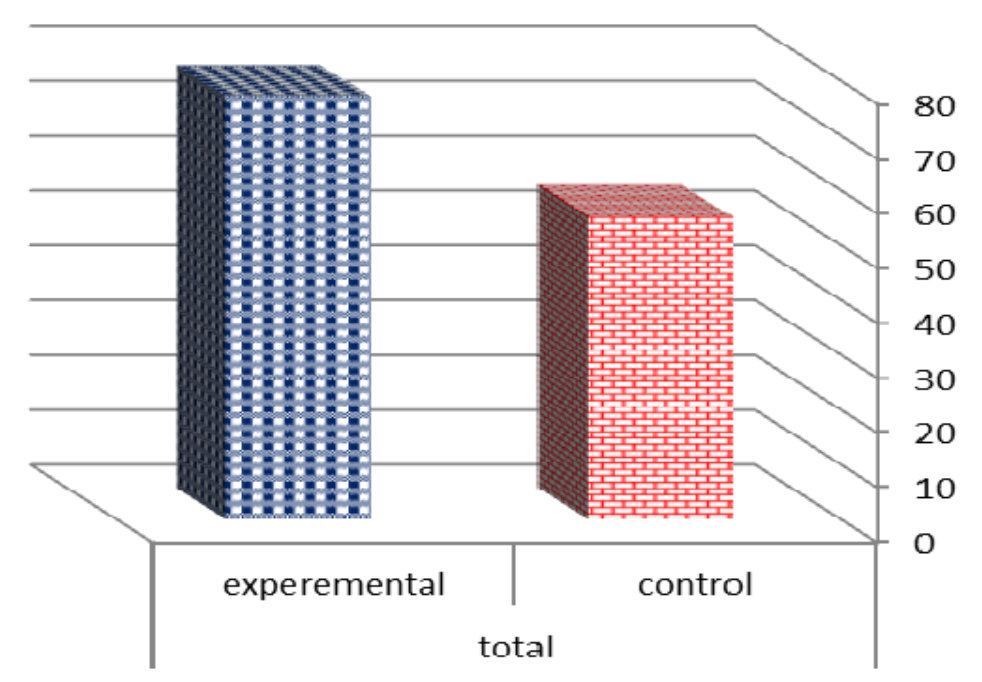

Figure 8. Comparison of Mean Scores of the Two Groups in the Post Administration of the Creative Writing Skills

\section{Conclusion}

The statistical analysis demonstrated that the ADDIE model applied in the e-learning environment proved to be effective for teaching creative writing as the experimental group's mean scores of the creative writing posttest improved significantly in favor of the experimental group in the overall test at the 0.01 level of significance. Results of the study indicated that the use of the web $\log$ as a medium of projecting students' writings in the instructional design of the ADDIE model functioned as an effective teaching and learning tool supportive to the process of creative writing. The e-learning environment of Blackboard blogs and discussion boards was thus effective in developing students' writing performance, gradually increasing their development of creative writing skills in English.

Results of the study showed significant difference between the mean scores of the experimental group in the pre-and-post administration of the CWT in overall creative writing skills. This indicates that the experimental group trained to use e-learning environment, achieved higher writing performance in terms of overall creative writing skills. Similarly, the amount of growth between the pre-test and posttest was significant in overall creative writing skills for the experimental group students. The effect of using e-learning environment is reflected in the high scores that the experimental group participants achieved. Some factors related to the suggested strategy and the implemented teaching/learning methodology seem to account for the registered progress in their overall creative writing skills.

In conclusion, the experimental participants were able to improve their creative writing performance by the end of the study compared with their peers in the control group. This may be attributed to the instructional design of the ADDIE model in the LMS of Blackboard which possibly induced the experimental participants to identify and emphasize their efforts of understanding the relationship between brainstormed ideas and to select proper transitional words and phrases to signal new ideas in paragraphs. As well, these findings can be attributed to both the features of the e-learning environment and benefits of the creative writing activities after the instructional design of the ADDIE model.

The researcher also noticed that experimental students' confidence increased when they were given the opportunity for practicing creative writing on their weblogs according to the e-learning strategy of ADDIE that was employed in this study. This could further be attributed to the asynchronous nature of weblogs that offered them more liberty and momentum to reread their own and their peers' projects without space or time constraints. This indicates that EFL learners tend to cooperate on their creative writing projects devotedly and passionately when they perceive that their writing teacher, other peers, and their weblog readers will have access to their work at anytime and anywhere. 
Pedagogically, the findings from this study suggest that EFL instructors should be mindful of the significance of e-learning resources and strategies inherent in the full utilization of Blackboard facilities including blogs and discussion boards as a teaching and learning tools supportive of the processes of reading and writing and for enhancing developing students' writing performance compared to the conventional method.

\section{References}

Abou Baker, A. (1996). Designing an English program to develop the reading and writing skills for university science students in Libya. Unpublished Ph.D. Dissertation, Ain Shams University, Cairo, Egypt.

AlAamri, K. (2010). Using web 2.0 technologies to enhance academic writing proficiency among ESL students in Sultan Qaboos University: An example of Facebook and blogs. A paper presented at the International Conference on the Future of Education, Florence, Italy. Retrieved from https://www.pixel /online.net/edu_future2012

Aljumah, F. (2011). Saudi learner perceptions and attitudes towards the use of blogs in teaching English writing course for EFL majors at Qassim University. [online] English Language Teaching, 5(1), 100-116. https://doi.org/10.5539/elt.v5n1p100

Allen, M. (2017). Designing Online Asynchronous Information Literacy Instruction Using the ADDIE Model. In T. Maddison, \& M. Kumaran (Eds.), Distributed Learning (pp. 69-91). Chandos Publishing: Elsevier. https://doi.org/10.1016/B978-0-08-100598-9.00004-0

Al-Meni, A. M. O. (2008). An investigation of the effect of computer-assisted writing instruction on EFL Saudi learners' ability. Unpublished M.A. Thesis, King Saud University, Riyadh, KSU.

Alothman, N. (2012). Investigating the Relationship between Creativity and Communicative Language Teaching Among EFL Learners in the College of Education in Kuwait. Journal of Educational and Psychological Sciences, 13(3), 11-33. https://doi.org/10.12785/JEPS/130319

Aly, M. (2002). The effect of using the writing workshop approach on developing student teachers composing skills. Proceedings of the 21st CDELT National Symposium on English Language Teaching: Meeting Challenges of ELT in the Arab World (pp. 131-169). Ain Shams University, Egypt.

Awamleh, Habis, Al Farah, Yacoub, \& El-Zraigat, Ibrahim. (2012). The Level of Creative Abilities Dimensions According to Torrance Formal Test (B) and Their Relationship with Some Variables (Sex, Age, GPA). International Education Studies, 5(6), 138-148. https://doi.org/10.5539/ies.v5n6p138

Benson, J., \& Reyman, J. (2009). Learning to Write Publicly: Promises and Pitfalls of Using Weblogs in the Composition Classroom. Retrieved from https://www.researchgate.net/publication/228879702_Learning_to_Write_Publicly_Promises_and_Pitfalls_ of_Using_Weblogs_in_the_Composition_Classroom

Branch, R. M. (2018). Characteristics of instructional design models. In R. A. Reiser, \& J. V. Dempsey (Eds.), Trends and issues in instructional design and technology (4th ed., p. 28). New York: Pearson Merrill Prentice Hall.

Bugis, Yosra. (2018). Creating digital stories with Saudi Arabian pre-service teachers: using the analysis, design, development, implementation, and evaluation model to promote lesson plan development. Unpublished doctoral dissertation. University of Northern Colorado. ProQuest Number: 10829604.

Campbell, P. C. (2014). Modifying ADDIE: Incorporating new technologies in library instruction. Public Services Quarterly, 10(2), 138-149. https://doi.org/10.1080/15228959.2014.904214

Ceserani, J. (2014). Creative Problem Solving. 1st ed. Bookboon.com.

Chevalier, R. D. (2011). When did ADDIE become addie? Performance Improvement, 50(6), 10-14. https://doi.org/10.1002/pfi.20221

Codone, S. (2001). An e-learning primer. Pensacola, FL: Raytheon Interactive.

Davis, A. L. (2013). Using instructional design principles to develop effective information literacy instruction: The ADDIE model. College \& Research Libraries News, 74(4), 205-207. https://doi.org/10.5860/crln.74.4.8934

Densky, K. (2003). Modern conceptions of creativity and communicative language teaching in an EAL setting. Unpublished MA Thesis, Simon Fraser University.

Dick, W., Carey, L., \& Carey, J. O. (2001). The systematic design of instruction (5th ed.). New York: Longman. 
Du, H., \& Wagner, C. (2007). Learning with Weblogs: Enhancing Cognitive and Social Knowledge Construction. IEEE Transactions on Professional Communication, 50(1), 1-16. https://doi.org/10.1109/TPC.2006.890848

Elola, I., \& Oskoz, A. (2010). Collaborative Writing: Fostering Foreign Language and Writing Conventions Development. Language Learning \& Technology, 14(3), 51-71.

Fageeh, A. (2011). EFL learners' use of blogging for developing writing skills and enhancing attitudes towards English learning: An exploratory study. [online] Journal of Language and Literature, 2(1), 31-48. Retrieved from https://ntdc.alazhar.edu.ps/upload/researches/JLL2011(1-5).pdf

Forsythe, E. (2014). Online intercultural collaborations using wikis: An analysis of students' comments and factors affective project success. The JALT CALL Journal, 10(3), 255-271. https://doi.org/10.29140/jaltcall.v10n3.179

Ghirardini, Beatrice. (2011). E-learning methodologies: A guide for designing and developing e-learning courses. Federal Ministry of Education, Rome.

Hall, R., \& Getts, E. (2017). A Model for Teaching Information Literacy in a Required Credit-Bearing Online Course. In T. Maddison, \& M. Kumaran (Eds.), Distributed Learning (pp. 111-122). Chandos Publishing, Elsevier. https://doi.org/10.1016/B978-0-08-100598-9.00006-4

Harper, V. B., \& Harper, E. J. (2006). Understanding student self-disclosure typology through blogging. The Qualitative Report, 251-261.

Helal, E. (2003). A proposed self-access reading program for developing English language writing skills for first year secondary students. Unpublished M.A. Thesis, Ain Shams University, Cairo, Egypt.

Henry, P. (2001). E-learning technology, content and services. Education and Training, 43(4/5), 249-255, https://doi.org/10.1108/EUM0000000005485

Hsu, T., Lee-Hsieh, J., Turton, M. A., \& Cheng, S. (2014). Using the ADDIE model to develop online continuing education courses on caring for nurses in Taiwan. Journal of Continuing Education in Nursing, 45(3), 124. https://doi.org/10.3928/00220124-20140219-04

Hung, C-M., Hwang, G-J., \& Huang, I. (2012). A project-based digital storytelling approach for improving students' learning motivation, problem-solving competence and learning achievement. Educational Technology \& Society, 15(4), 368-379. Retrieved from https://0-search.proquest.com.source.unco.edu

Ibnian, Salem Khalaf. (2011). The Effectiveness of a Proposed Program Based on the Problem Solving Strategy in Developing Tenth Grade Students' Creative Writing. Theory and Practice in Language Studies, 1(3), 263-272.

Ismail, N., Hussin, S., \& Darus, S. (2012). ESL students' attitudes, learning problems, and needs for online writing. [online] GEMA Online ${ }^{\mathrm{TM}}$. Journal of Language Studies, 12(4), 1089-1107. Retrieved from https://www.researchgate.net/publication/235987677_ESL_Students\%27_Attitude_Learning_Problems_An d_Needs_For_Online_Writing

Itmazi, J. A., \& M. M. Gea. (2005). Survey: Comparison and Evaluation Studies of Learning Content Management Systems. MICROLEARNING2005: Learning \& Working in New Media Environments. International Conference, Innsbruck, Austria.

Jameel, A. (2017). The Effect of Flexibility and Fluency Strategies on Developing Creative Writing Skills in English Language Subject of the Fourth Preparatory Literary Students. International Journal of Humanities and Applied Social Science, 2(1), 37-50.

Kavaliauskienè, G., Anusienė, L., \& Mažeikienė, V. (2006). Application of Blogging for Learner Development. Journal of Language and Learning, 4(2), 133-143.

Khadimally, S. (2015). Designing effective curricula with an interactive collaborative curriculum design tool (CCDT). TOJET: The Turkish Online Journal of Educational Technology, 14(3), 32-62.

Khater, A. (2002). A suggested program to develop reading and writing skills for English language major in light of counter-based instruction. Unpublished Ph.D. Dissertation, Ain Shams University, Cairo, Egypt.

Kulprasit, W., \& Chiramanee, T. (2012). Boosting EFL students' positive attitudes towards writing in English: The role of journal writing with peer feedback. ABAC Journal, 32(3), 20-28. Retrieved from 
https://www.abacjournal.au.edu/2012/sep2012/02_(20-28)\%20Boosting\%20EFL\%20Students\%20Positive. pdf

Larsen-Freeman, D. (1997). Chaos/complexity theory for second language acquisition. Encyclopedia of Applied Linguistics, 18(2), 141-165. https://doi.org/10.1093/applin/18.2.141

Lin, Meng-ying. (2015). Collaborative Writing in a Computer-Supported Classroom: Mediation, and Self-Assessed Beliefs and Attitudes about Writing. Unpublished doctoral dissertation. University of Toronto.

Lin, Y. (2007). An exploratory study of English multimedia writing: Implementing weblogs in a college composition class. Published master's thesis: National Tsing Hua University, Taiwan. Retrieved from https://www.hss.nthu.edu.tw/ fl/thesis/tesol/945260.pdf

Lipschutz, B. D. (2010). The use of digital storytelling to improve the effectiveness of social and conflict resolution skills training for elementary students (Doctoral dissertation). Retrieved from ProQuest Dissertations \& Theses Global. (UMI NO. 3408729).

Madison, T., \& Kumaran, M. (2017). Distributed Learning: Introduction (pp. 1-10). Chandos Publishing, Elsevier. https://doi.org/10.1016/B978-0-08-100598-9.00001-5

Moradmand, N., Datta, A., \& Oakley, G. (2014). The design and implementation of an educational multimedia mathematics software: Using ADDIE to guide instructional system design. The Journal of Applied Instructional Design, 4(1), 37-49.

Mourtaga, K. (2010). Poor writing in English: A case of the Palestinian EFL learners in the Gaza Strip. Proceedings of the First National Conference on: Improving TEFL Methods \& Practices at Palestinian Universities. Alquds Open University, Gaza. Retrieved from https://www.qou.edu/english/conferences/.../kamalMourtraga.pdf

Mynard, J. (2007). A Blog as a Tool for Reflection of English language Learners. Asian EFL Journal, 24, 1-10. Retrieved from https://www.asian-efl-journal.com/pta_Nov_07_jm.pdf

Naidu, S. (2006). E-Learning: A Guidebook of Principles, Procedures and Practices (2nd Revised ed.). New Delhi: Commonwealth Educational Media Center for Asia (CEMCA).

Oravec, J. (2002). Bookmarking the World: Weblog Applications in Education. Journal of Adolescent and Adult Literacy, 45(7), 616-621.

Oravec, J. (2003). Blending by blogging: Weblogs in blended learning initiatives. Journal of Educational Media, 28(2-3), 225-233. https://doi.org/10.1080/1358165032000165671

Peterson, C. (2003). Bringing ADDIE to life: Instructional design at its best. Journal of Educational Multimedia and Hypermedia, 12(3), 227-241. Retrieved from https://xt9lp6eh4r.search.serialssolutions.com

Pinkman, K. (2005). Using blogs in the foreign language classroom: Encouraging learner independence. The JALT CALL Journal, 1(1), 12-24. https://doi.org/10.29140/jaltcall.v1n1.2

Salehi, H., Asgariri, M., \& Amini, M. (2015). Impacts of the Extensive Reading Texts on the Writing Performance of Iranian EFL Pre-university Students. Asian Journal of Education and e-Learning, 3(4), 306-316.

Sato, K., \& Kleinsasser, R. (1999). Communicative language teaching (CLT): practical understandings. The Modern Language Journal, 83(4), 494-517. https://doi.org/10.1111/0026-7902.00037

Savignon, S. J. (1993). Communicative language teaching: State of the art. In S. Silberstein (Ed.), State of the art TESOL essays: Celebrating 25 years of the discipline (pp. 35-51). Alexandria, VA: TESOL.

Schlepphege, J. (2009). Creative Poetry Writing in the EFL Classroom. Munich, GRIN Verlag. Retrieved from https://www.grin.com/document/141016

Taura, T., \& Nagai, Y. (2010). Discussion on direction of design creativity research: New definition of design and creativity - Beyond the problem-solving paradigm. Springer, 3-8. https://doi.org/10.1007/978-0-85729-224-7_1

Temizkan, M. (2011). The Effect of Creative Writing Activities on the Story Writing Skill. Educational Sciences: Theory and Practice, 11(2), 933-939.

Thatcher, B. L. (2000). L2 professional writing in US and South America context. Journal of Second language writing, 9, 41-69. https://doi.org/10.1016/S1060-3743(99)00019-3 
Tsai, Jui-min. (2006). Connecting Reading and Writing in College EFL Courses. The Internet TESL Journal, XII(12). [Online] Retrieved from https://iteslj.org/Articles/Tsai-ReadingWritingConnection.html

Wang, S., \& Hsu, H. (2009). Using the ADDIE model to design second life activities for online learners. Washington, DC: Springer. https://doi.org/10.1007/s11528-009-0347-x

Ward, J. M. (2004). Blog Assisted Language Learning (BALL): Push Button Publishing for the Pupils. TEFL Web Journal, 3(1), 1-6.

Wiphasith, H., Narumol, R., \& Sumalee, C. (2016). The design of the contents of an e-learning for teaching M.5 English language using ADDIE model. International Journal of Information and Education Technology, 6(2), 127-131. https://doi.org/10.7763/IJIET.2016.V6.671

Zamel, V. (1983). Teaching those missing links in writing. ELT Journal, 37, 22-29. https://doi.org/10.1093/elt/37.1.22

Zamel, V. (1982). Writing: The process of discovering meaning. TESOL Quarterly, 16, 195-209. https://doi.org/10.2307/3586792

Zhang, D. (2009). The Application of Blog in English Writing. Journal of Cambridge Studies, 4(1). Retrieved from https://citeseerx.ist.psu.edu/viewdoc/download?doi=10.1.1.460.7646\&rep=rep1\&type=pdf

Zheng, D. (2012). Caring in the dynamics of design and languaging: Exploring second language learning in 3D virtual spaces. Lang Sci, 34(5), 543-558. https://doi.org/10.1016/j.langsci.2012.03.010

\section{Copyrights}

Copyright for this article is retained by the author(s), with first publication rights granted to the journal.

This is an open-access article distributed under the terms and conditions of the Creative Commons Attribution license (http://creativecommons.org/licenses/by/4.0/). 